\title{
Six-Legged Animaloid Robot as a Trainer for Robotic Course
}

\author{
Siti Sendari ${ }^{\text {a,1, }}$, Hakkun Elmunsyah ${ }^{\text {a,2, }}$, Yogi Dwi Mahandi ${ }^{\text {a,3 }}$ \\ ${ }^{a}$ Electrical Engineering Department, State University of Malang \\ Jl. Semarang 5, Malang 65145, INDONESIA \\ ${ }^{1}$ siti.sendari.ft@um.ac.id, 2hakkun@um.ac.id, ${ }^{3}$ yogidwimahandi@gmail.com
}

\begin{abstract}
The innovation of robot technology attracts students to study and participate in many robot contests. Thus, robotic trainer is very urgent to be developed, especially an animaloid robot, which can encourage both of robotics course and robot contest. Here, the trainer was developed using seven steps of ten steps, i.e., (1) potential and problem, (2) data collection, (3) product design, (4) design validity, (5) design revision, (6) product trials, and (7) product revision. The developed trainer is a sixlegged animaloid robot, which consists of five learning modules, i.e., (1) master-slave communication, (2) ultrasonic ranger, (3) motor servos, (4) flame sensors, and (5) extinguisher. The trainer was evaluated by media and material experts, where the validation results are $94 \%$ and $90 \%$, respectively, while the validation result in the implementation stage is $87.31 \%$. The result can be concluded that developed trainer is feasible and can be used as the learning media.
\end{abstract}

Index Terms - six-legged animaloid robot, hexapod robot, robotic course, learning media

\section{Introduction}

Robotic Innovation has been enhancing since1990, which starts as industrial tools and becoming as home appliances [11].This enhancement attracts students to study robotic course indicated by many of them attended competitions in the robotic field, such as Indonesian Robotics Competition held by The Directorate of Higher Education.

Robotics is one of compulsory courses at the Department of Electrical Engineering, State University of Malang (called as the TE-FTUM). The course provides mechanical and electrical circuits, and the algorithms of movements. A robotics lab is available to support the robotics course, where some trainers of line follower and arm robots are developed. However, these modules are not enough to cover all competencies, especially for supporting robot contests. In order to support the competency of hardware and software troubleshooting, the "learning by doing" is a suitable method for teaching robotics [12]. Thus, trainers which support the learning course and robotics competition are needed. The trainers will be used as experiment tools, which could improve the knowledge of students.

Robotics can be classified as (1) non-mobile robot, (2) mobile robot, (3) combination of non-mobile and mobile robots, and (4) extraordinary robot [10]. Here, humanoid and animaloid as extraordinary robots are needed to be developed at the TE-FTUM, while developing an animaloid robot is the main focus in this paper. Based on this reason, the six-legged animaloid robot, which imitates the movement of an insect [8] is developed.

Fundamental Objectives of Engineering Laboratoraries
The goal of engineering education is to develop students to advance their practice skills. It has been studied that the emphasis of laboratory has been paid by the curriculum and teaching methods, while there is a still lack of laboratory instruction. Laboratories have to be the central role in education of engineers therefore laboratories can not be forgone completely [6]. There are three basic types of engineering laboratories, i.e., development, research, and educational, where students do the practices to extract data for a design, to evaluate devices, or to discover a new knowledge.

Feisel explained that the fundamental objectives of engineering laboratories consist of 13 points of the cognitive domain, i.e., (1) instrumentation, (2) models, (3) experiment, (4) data analysis, (5) design, (6) learn from failure, (7) creativity, (8) psychomotor, (9) safety, (10) communication, (11) teamwork, (12) ethics in the laboratory, and (13) sensory awareness. The first five of those objectives are dealing with cognitive domain, i.e., instrumentation, models, experiment, data analysis, and design. The other two are specified as psychomotor domain, i.e. psychomotor and sensory awareness, while the remaining objectives determine affective domain, i.e., behaviour and attitudes, learn from failure, creativity, safety, communication, teamwork, and ethics in the laboratory. Using these objectives as a framework, laboratory developers and educational researchers can identify the specific objectives, which work like expectation by engineering education community.

\section{Research Method}

In order to obtain the goals of engineering laboratories, developing robot trainer is needed to advance the practice skills of the students in robotic course. The trainer in this research is developed based on Sugiyono's model [14], where the steps are (1) potential and problem, (2) data collection, (3) product design, (4) design validity, (5) design revision, (6) product trials, and (7) product revision.

The objective of developing the six-legged robot trainer is to support the learning course, however the trainer also should be able to participate in the national robot competition held by the Directorate of Higher Education of Indonesia. Then, parameter data for developing trainer is selected based on the requirements of the Fire -fighting Robot in 2014.

Robot Institute of America (RIA) present the definition of a robot, i.e., a reprogrammable, multifunctional function designed to move material, parts, tools, or specialized devices through various programmed functions for the performance of a variety of tasks. Considering this 
definition, the trainer is developed into three parts, i.e., (1) Mechanics to interact with environments, (2) Sensor to perceive environments, (3) Control systems of mechanics and sensor data.

The trainer is validated by the experts in the TE-FTUM, i.e., media and material experts. After some revisions, the trainer is implemented to the robotic class consisting of 43 students, and the implementation result is analyzed. The data and instrument types are shown in Table 1.

Table 1. Data And Instrumentation Type

\begin{tabular}{|l|c|c|c|}
\hline \multirow{2}{*}{ Subject } & \multicolumn{2}{|c|}{ Data Type } & \multirow{2}{*}{ Instruments } \\
\cline { 2 - 3 } & Quantitative & Qualitative & \\
\hline Media Expert & $\checkmark$ & $\checkmark$ & Questionnaire \\
\hline Material Expert & $\checkmark$ & $\checkmark$ & Questionnaire \\
\hline Respondent (Students) & $\checkmark$ & $\checkmark$ & Questionnaire \\
\hline
\end{tabular}

The quantitative data is analyzed based on questionnaire scores according to the method explained by Akbar [1], that is, validity is determined by the number of questionnaire items and Linkert scale used by. The validation is determined using Eq. (1) and (2) as follows.

$\Delta$ Score $=\left(N \_\right.$item $\times$Max_Score $)-\left(N \_i t e m \times\right.$ Min_Score $)$

$$
\text { Class_Interval }=\Delta \text { Score } / \text { Linkert }_{\text {Scale }} \text { (2) }
$$

Where, N_item, Max_Score, and Min_Score represent the number of questionnaire items, maximum and minimum score in each item, respectively, while $\Delta$ Score calculates the deviation between those scores. The percentage of validity is determined by the rate of score in class interval and maximum score as shown in Eq. (3).

Validity $(\%)=$ Class_Interval_Score / Max_Score x 100\%

Based on those equations above, the validation criteria of media and material experts are shown in Table 2. The validation in the implementation is also categorized using Table 2. [3]

Table 2. Validation Criteria Of Media And Material Experts

\begin{tabular}{|l|l|l|}
\hline \multicolumn{1}{|c|}{ Validity (\%) } & \multicolumn{1}{|c|}{ Criteria } & \multicolumn{1}{c|}{ Description } \\
\hline $81.26 \%-100.00 \%$ & Valid & Revision is not needed \\
\hline $63.51 \%-81.25 \%$ & Enough & Minor revision \\
\hline $43.76 \%-62.50 \%$ & Less & Major revision \\
\hline $25.00 \%-43.75 \%$ & Not valid & Total revision \\
\hline
\end{tabular}

\section{Developing Animaloid Robot Trainer}

The developed animaloid robot here is called as the sixlegged robot, which imitates of insect. The robot moves using six legs, where each leg is developed by two degree of freedom (2-DOF), while another case, can be three DOF. DOF means robot's joints coupled with servo motors and constructed like a leg of animal. The six-legged robot is shown in Fig. 1.
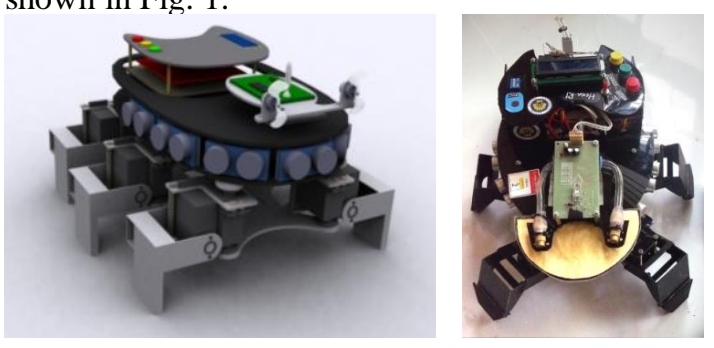

Fig. 1. The six-legged robot.

\section{A. Developing Mechanics of the Six-legged Robot}

The developed robot here is the six-legged robot with 2DOF for each leg. The servo motors are coupled at each joint, as shown in Fig. 2(a). Actuator 1 makes the robot to move forward or backward representing " $x$ " axis at the Cartesian graph, while actuator 2 makes it to move up or down representing " $\mathrm{z}$ " axis. Here, the designed robot uses twelve servo motors, i.e., Towerpro series (MG946R), where the motors are assembled as six legs and 2-DOF for each leg. Each motor can turn until 180 degree. The motors are assembled to the robot as shown in Fig. 2(b). This construction can be enhanced to 3-DOF while one DOF is added to the each leg. Three-DOF makes the robot moves more flexible to the right or left, however it will be expensive.

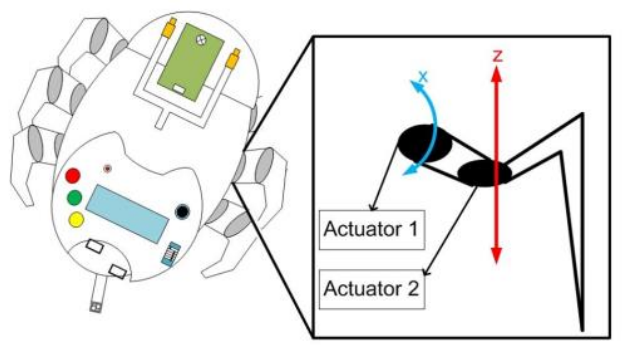

(a)

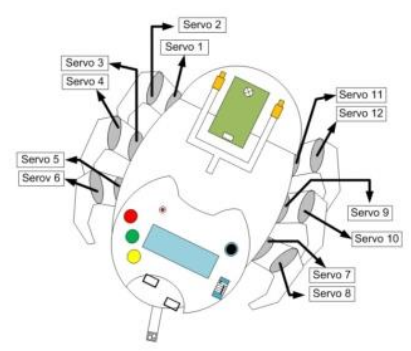

(b)

Fig. 2. Mechanics of six-legged robot (Hexapod). (a) using 2-DOF (b) assembling servo motors to the six-legged robot.

1. The moving model of the six-legged robot in its environment is called gait, i.e., a sequence of foot contacts with the ground, which produces motion patterns [7]. There are three types of gaits, i.e., (1) metachronal gait, (2) ripple gait, and (3) tripod gait. The typical of those gaits' patterns are shown in Fig. 3 , where white color indicates that the foot is in ground contact. Among those types, tripod gait shows the fastest speed [4].

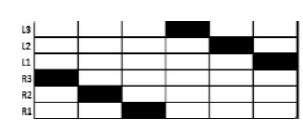

(a)

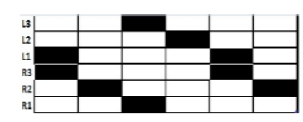

(b)

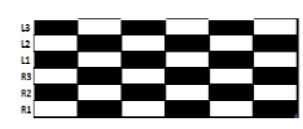

(c)

Fig. 3. Giat diagram (a) Metachonal giat (b) Ripple gait (c) Tripod gait 
The metachronal gait is a pattern where each leg only lifts when the leg behind it is on the ground position to support the animal weight. So it can be seen as the wave which starts from the back and is transferred forward as each leg in turn of lifts. This pattern provides stability while decrease energy expenditure [9]. The ripple gait is a pattern of robot locomotion where two legs at a time have two independent wave gaits, which means that the opposite side legs are 180 degrees out of phase, and each leg needs three beats to complete one cycle [2]. The tripod gait is used by mostly insects, which hold a stable triangle of legs steady while swinging the opposite triangle forwards [13].

\section{B. Sensor Assembling}

In order to perceive the environment, the robot is equipped with eight ultrasonic sensors, which return the information of the obstacles' distance in front, behind, left side and right side of it. Here, ultrasonic sensors of Devantech SRF04 are used, which have capability to detect obstacles in the range between $2 \mathrm{~cm}$ and $400 \mathrm{~cm}$. The sensors are assembled as shown in Fig. 4.

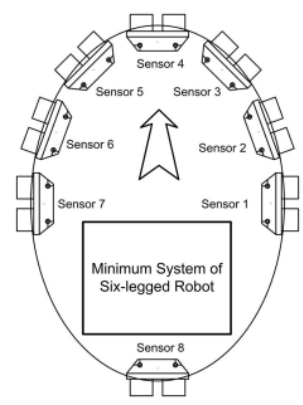

Fig. 4. Ultrasonic sensors assembling

Another sensor assembled to the robot is a flame detector. When the sensor detects ultraviolet (UV) emission, UV photons in sufficient quantity strike the negative electrode. Then, electrons are released from the electrode and attracted to the positive electrode. While this situation occurs, the sensor returns logic " 1 " until the output is reset.

\section{Minimum Systems for Controling the Six-Legged Robot}

The minimum system of the robot is separated in two parts, i.e. the master part and slave part. The master part serves the main control to handle servo motors, addition buttons, flame detector, display panel, front and rear sensor, sound activation ad extinguisher. While the slave part serves eight ultrasonic sensors. Here, DT-AVR ATmega1280 and ATmega128 are used to the master and slave part of minimum systems, respectively. ATmega128 has fewer input/output channels; therefore, it is only used to detect eight ultrasonic sensors. The diagram block of the minimum systems is shown in Fig.5.

Here, the six-legged robot is designed to be a fire fighter, which should extinguish the fire. The robot starts to works when sound activation is detected. First, the robot should detect where the start location, and the appropriate strategy will be selected. The robot scans the wall and moves following the wall using the tripod gait mode. The robot enters the rooms and detects the fire if there is a flame emission. While the flame is detected, the robot will spray water to extinguish the fire. Then, the robot will move back to the start location. The trial of this algorithm is shown Fig. 6.

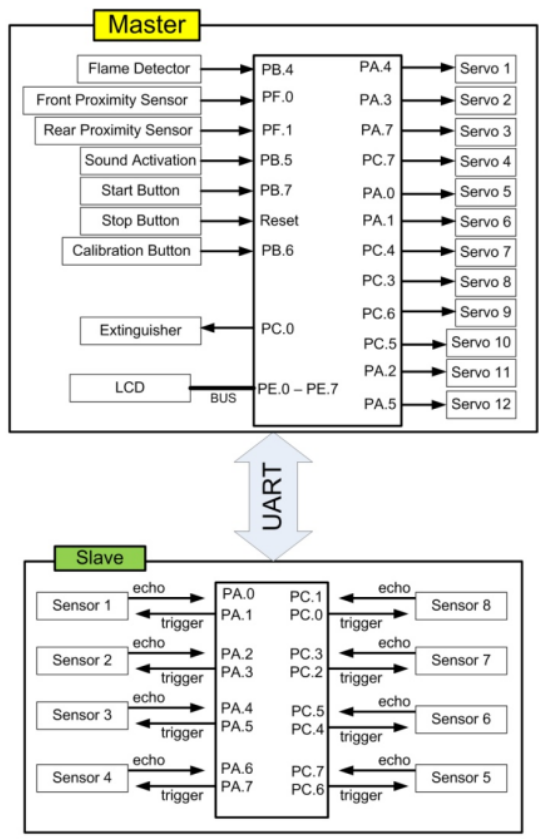

Fig. 5. Minimum system of six-legged robot

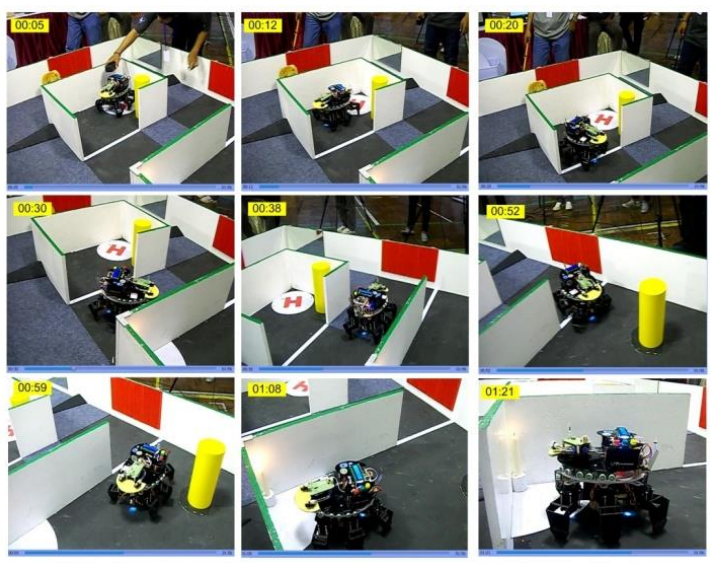

Fig. 6. Trial result of controlling the sic-legged robot

\section{Validation Results}

Developing the six-legged robot in this paper is to realize a robot trainer, which can support the robotic course in the TE-FTUM. The trainer is accomplished with a module and job sheets elaborated into five experiments, i.e., (1) Master-Slave Controlling, (2) Ultrasonic sensors to perceive environments, (3) Servo motors as actuators of the six-legged robot, (4) Assembling a flame detector to detect the Fire, and (5) Algorithms of the six-legged robot as a fire fighter. The trainer is validated by the experts in TEUM, i.e., media and material experts.

The instrument of media validation was developed using 40 items including three aspects of learning media assessment, i.e., engineering, learning design, and visual communication [15]. On the other hand, the instrument of material validation was developed using 25 items including instructional goals and objectives, student engagement, 
methodology for active learning, suitable for its intended purpose, and organizing the structure of material [5]. In the implementation stage, the students were given a questionnaire consisting 30 items, which collect the information of their understanding and opinion to the trainer utilization. The validation data of designing the trainer and its module are shown in Fig. 7.

According to Table 2 and media validation data as shown in Fig.7(a), the trainer could be valid and feasible to be used for lecturing with percentage of $94 \%$, while the experts media suggest to improve the trainer using modular model, that is, the program is divided into several blocks accomplished with the explanation. Furthermore, the material validation data as shown in Fig.7(b) could confirm that validation was be also valid and feasible to be used for lecturing with percentage $90 \%$.

In the implementation stage, the validation result is $87.31 \%$, which means that the trainer was valid to be implemented in lecturing. From 43 students, 34 students said that they enjoy study using the trainer, while remain students suggest to arrange appropriate groups to improve the student's engagement.

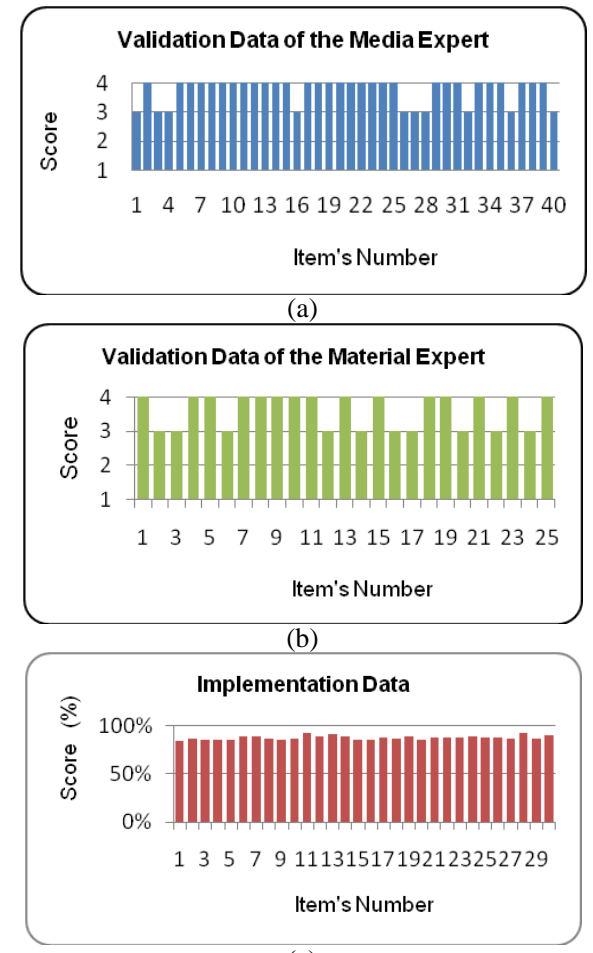

(c)

Fig. 7. Validation data of the trainer and its module

\section{Conclusion}

Robotics course at the TE-FTUM provides lecturing of mechanical, electrical circuits, and the algorithms of movements. In order to cover all competencies in robotic skills an also to support the robotic contest, the six-legged animaloid robot was designed. The designed trainer was accomplished with five learning modules, i.e., (1) masterslave communication, (2) ultrasonic ranger, (3) motor servos, (4) flame sensors, and (5) extinguisher. The results show that the trainer is valid to be used as a media and material learning for supporting robotic course, which covers the competency of troubleshooting of hardware and software. In this research, the learning by doing is a suitable method for teaching robotics.

\section{References}

[1] Akbar Sa'dun, "Instrumen Perangkat Pembelajaran," Remaja Rosdakarya Offset. Bandung, 2013.

[2] Aparna, Kale and Geeta, Salunke. "Insect Inspired Hexapod Robot for Terrain Navigation", International Journal of Research in Engineering and Technology, vol. 02, issue 08, pp. 63-69, 2013.

[3] Arikunto, Suharsimi. "Dasar-Dasar Evaluasi Pendidikan (Edisi Revisi)". Bumi Aksara, 2010.

[4] Campos, Ricardo; Matos, Vitor; Oliveira, Miguel; and Santos, Cristina. "Gait Generation for A Simulated Hexapod Robot: A Nonlinear Dynamical Systems Approach". Research Report of the Portuguese Science Foundation (grant PTDC/EEACRO100655/2008)

[5] Davies, Judy. "Evaluation and Selection of Learning Resources: A Guide", Canada: Prince Edward Island Department of Education, 2008 .

[6] Feisel, Lyle D. and Rosa, Albert J. "The Role of the laboratory in Undergraduate Engineering Education", Journal of Engineering Education, Vol. 94, Issue 1, pp. 121-130, 2005.

[7] Haynes, G. Clark, and Rizzi, Alfred A. "Gaits and Gait Transitions for Legged Robots", in Proc. Of the IEEE Conference on Robotics and Automation, Orlando-Florida, USA, 2006.

[8] Jakimovski, Bojan "Biologically Inspired Approaches for Locomotion, Anomaly Detection and Reconfiguration for Walking Robots". Berlin Heidelberg: Springer, 2011.

[9] Parker, Gary B, and Mills, Jonathan W "Metachronal Wave Gait Generation for Hexapod Robots", Research Report of NSF Graduate Reasearch Traineeship Grant GER93-54898, 1998.

[10] Pitowarno, Endra "ROBOTIKA: Desainn, Kontrol dan Kecerdasan Buatan". Yogyakarta: ANDI, 2006.

[11] Sargent G.: Robotics History Timeline. Robotics Research Group Designing Robot Assistant to Help People. http://robotics. ece. auckland. ac.nz/index.php? option=com_content\&task=view\&id=31 accessed December 17, 2013. Schank, R C. "Learning by Doing in Book of Instructional-Design Theories and Models: New paradigm of Instructional Theory", Vol. 2. Mahwah: Lawrence Erlbaum Associates, Inc., 1999.

[12] Smolka, Jochen; Byrne, Marcus J.; Scholtz, Clarke H., "A New Galloping Gait in an Insect”. Current Biology, Vol. 23:20, pp. R913R915, 2013

[13] Sugiyono. "Metode Penelitian Kuantitatif, Kualitatif, dan R\&D". Bandung: Penerbit Alfabeta, 2011

[14] Wahono, Romi Satria "Aspects and Criteria of Learning Media Assessment”, http://romisatriawahono.net/2006/06/21/aspek-dankriteria-penilaian-media-pembelajaran/, accessed July 1st, 2014 